\title{
Three-component coupling of aryl iodides, allenes, and aldehydes catalyzed by a Co/Cr-hybrid catalyst
}

\author{
Kimihiro Komeyama*, Shunsuke Sakiyama, Kento Iwashita, Itaru Osaka and Ken Takaki
}

\section{Full Research Paper}

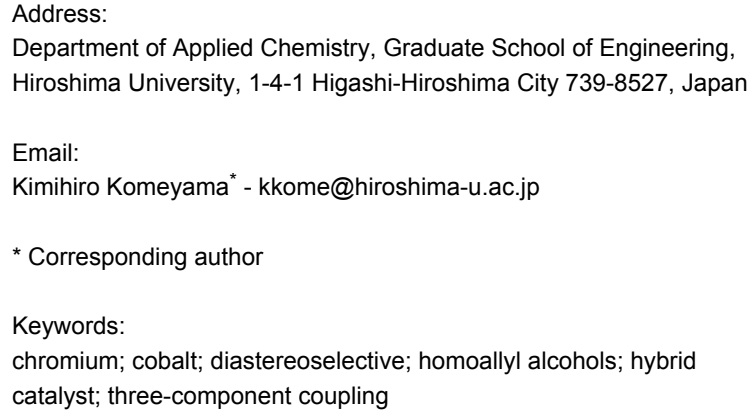

Beilstein J. Org. Chem. 2018, 14, 1413-1420.

doi:10.3762/bjoc. 14.118

Received: 15 March 2018

Accepted: 22 May 2018

Published: 11 June 2018

This article is part of the thematic issue "Cobalt catalysis".

Guest Editor: S. Matsunaga

(c) 2018 Komeyama et al.; licensee Beilstein-Institut. License and terms: see end of document.

\begin{abstract}
The cobalt/chromium-catalyzed three-component coupling of aryl iodides, allenes, and aldehydes has been developed to afford multi-substituted homoallylic alcohols in a diastereoselective manner. Control experiments for understanding the reaction mechanism reveal that the cobalt catalyst is involved in the oxidative addition and carbometalation steps in the reaction, whereas the chromium salt generates highly nucleophilic allylchromium intermediates from allylcobalt species, without the loss of stereochemical information, to allow the addition to aldehydes.
\end{abstract}

\section{Introduction}

Carbon-carbon bond formation is the fundamental and central transformation of synthetic organic chemistry. The elaboration and extension of a carbon framework via a series of carbon-carbon bond-forming reactions are extremely important for medicinal chemistry and agrochemical and natural product synthesis. In these bond formations, organometallics play an essential role because they possess various reactivities depending on the central metal ions that they own. For example, carbon has strong nucleophilicity when bonded to metals with low electronegativity, as demonstrated in the reaction of organolithium, organomagnesium, organozinc, and organochromium $\mathbf{A}$, to facilitate addition reactions of appropriate carbon electrophiles such as aldehydes (Scheme 1, top) [1]. In contrast, $\pi$-electrophilic carbon-connected late transition metals $\mathbf{B}$ facilitate the carbometalation of carbon-carbon multiple bonds, leading to multi-substituted carbon frameworks (Scheme 1, bottom) [2,3]. The nucleophilic and $\pi$-electrophilic organometallic intermediates are used properly in their favorable circumstances.

Transmetalation is one of the most vital elemental processes used to drastically change the reactivity of organometallics, involving a wide range of transition metal-catalyzed reactions. For example, transmetalation between an organonickel (or organocobalt) complex and chromium salt results in the forma- 


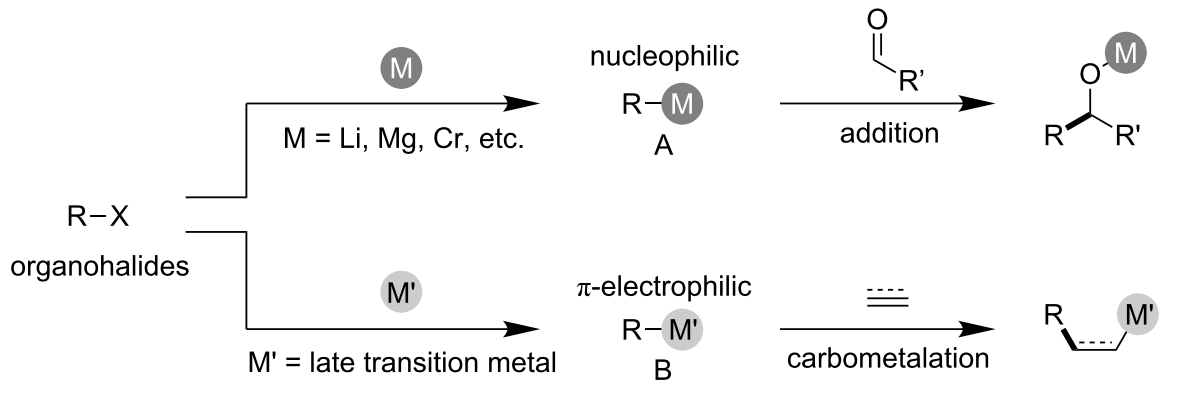

Scheme 1: Nucleophilic and m-electrophilic characters of organometallics depending on the central metals.

tion of a highly nucleophilic organochromium species, which enables efficient addition to aldehydes to give substituted secondary alcohols, as demonstrated in the Nozaki-Hiyama-Kishi (NHK) reaction (Scheme 2) [4-9]. Although the catalyst combination allows the use of organic halides as carbon nucleophiles, a multicomponent coupling reaction using a similar catalyst combination has had limited success [10-12].

We have recently demonstrated the high $\pi$-electron affinity of an organocobalt species that enabled a variety of alkyne functionalization reactions to proceed via carbocobaltation (Scheme 3) [13-15]. Furthermore, a combination of the cobalt and chromium catalyst could be applied to alkynyl iodoarene cyclization/borylation to form cyclized vinylboronic esters, in which transmetalation between the generated vinylcobalt and chromium salt was a critical step (Scheme 4) [16]. As part of our continuing work on the cobalt-catalyzed functionalization of carbon-carbon unsaturated bonds, a three-component coupling method is herein reported for the direct synthesis of highly diastereoselective multi-substituted homoallyl alcohols employing a cobalt/chromium hybrid catalyst (Scheme 5).

\section{Results and Discussion}

Initially, suitable reaction conditions were investigated for the three-component coupling reaction between iodobenzene (1a), 5-phenylpenta-1,2-diene (2a), and 4-methylbenzaldehyde (3a) in the presence of $\mathrm{CoBr}_{2}(10 \mathrm{~mol} \%), \mathrm{CrCl}_{3}(20 \mathrm{~mol} \%)$, and manganese powder (2.0 equiv), using trimethylsilyl chloride (TMSCl, 1.2 equiv) as a trapping reagent [7]. These results are summarized in Table 1 . The absence of a ligand afforded the homoallyl alcohol 4a in 25\% yield as a syn/anti (80:20) mixture of diastereomers, the ratio of which was determined by the coupling constant between the two protons at the $\mathrm{C} 1$ - and C2-positions of $4 \mathbf{a}$; a coupling value of ${ }^{3} J=$ ca. $5.0 \mathrm{~Hz}$ indicated the $s y n$-form, and a coupling value of ${ }^{3} J=c a .8 .0 \mathrm{~Hz}$ indicated the anti-form (Table 1, entry 1) [17]. The addition of $\mathrm{PPh}_{3}$ (20 mol \%) resulted in an increase in the product yield to $45 \%$ with a similarly diastereomer ratio (Table 1 , entry 2 ). The use of

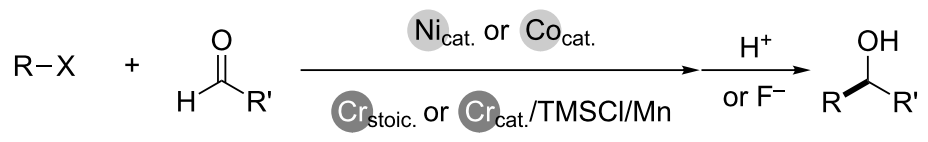

Scheme 2: Ni/Cr or Co/Cr-catalyzed NHK reaction.

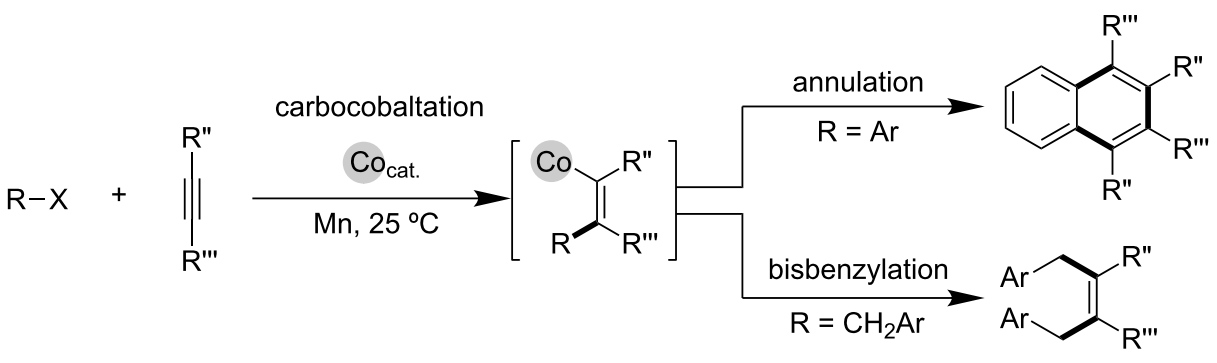




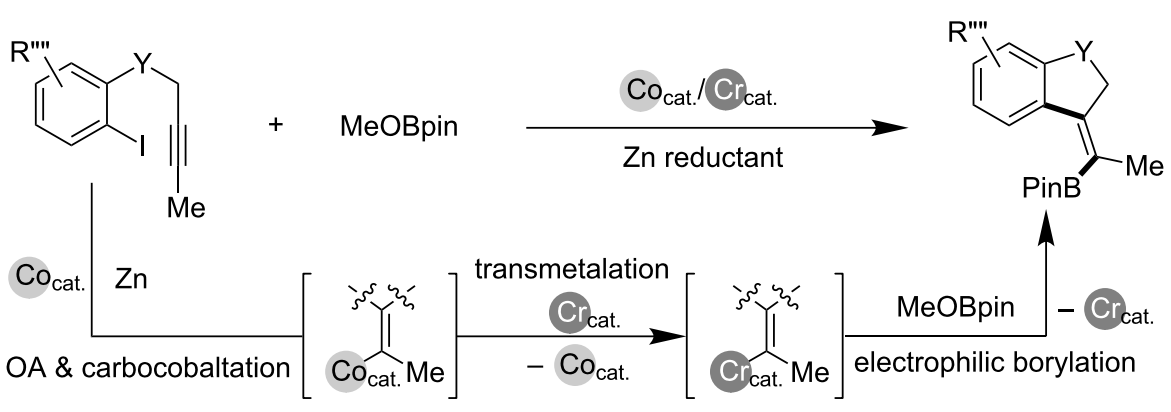

Scheme 4: Cyclization/borylation of alkynyl iodoarenes using the $\mathrm{Co} / \mathrm{Cr}$ catalyst.

$$
\mathrm{Ar}-\mathrm{I}+\underbrace{\mathrm{R}}_{\nabla^{\prime}}+\mathrm{R}^{\prime} \mathrm{CHO} \frac{\mathrm{Co}_{\text {cat. }} / \mathrm{Cr}_{\text {cat. }}}{\mathrm{Mn}, \mathrm{TMSCl}}
$$

Scheme 5: Three-component coupling of aryl iodides, arenes, and aldehydes using $\mathrm{Co} / \mathrm{Cr}$ catalyst (this work).

the chromium catalyst, Mn reductant, and TMSCl was crucial for the coupling (Table 1, entries 3-5). Thus, the removal of $\mathrm{CrCl}_{3}$ resulted in the formation of a trace amount of $\mathbf{4 a}$ with the complete consumption of allene $\mathbf{2 a}$, whereas most of iodoarene 1a and aldehyde 3a remained unreacted after the reaction was completed (Table 1, entry 3 ). Using a $\mathrm{Zn}$ reductant instead of $\mathrm{Mn}$ resulted in a negligible amount of coupling product (Table 1, entry 4), wherein 1a was completely consumed [18]. Reaction conditions without the use of TMSCl produced $\mathbf{4 a}$ in a catalytic amount (Table 1, entry 5). Other ligands were also tested (Table 1, entries 5-12), and after the screening of several phosphines and pyridine-type ligands, the latter ligands were found to be the most effective for use in the coupling reaction. Consequently, we found that iminopyridine $\mathbf{L} 3$ was the best choice of ligand, and when used, it resulted in the three-component product 4a being obtained in $69 \%$ yield with a diastereoselectivity ratio of 92:8 (Table 1, entry 13). Additionally, preformed $\mathrm{CoBr}_{2}(\mathbf{L 3})$ gave a similar result (Table 1, entry 14). During the transformation, the chromium catalyst ligands inhibited the reaction (Table 1, entries 15-17). Also, the reaction was

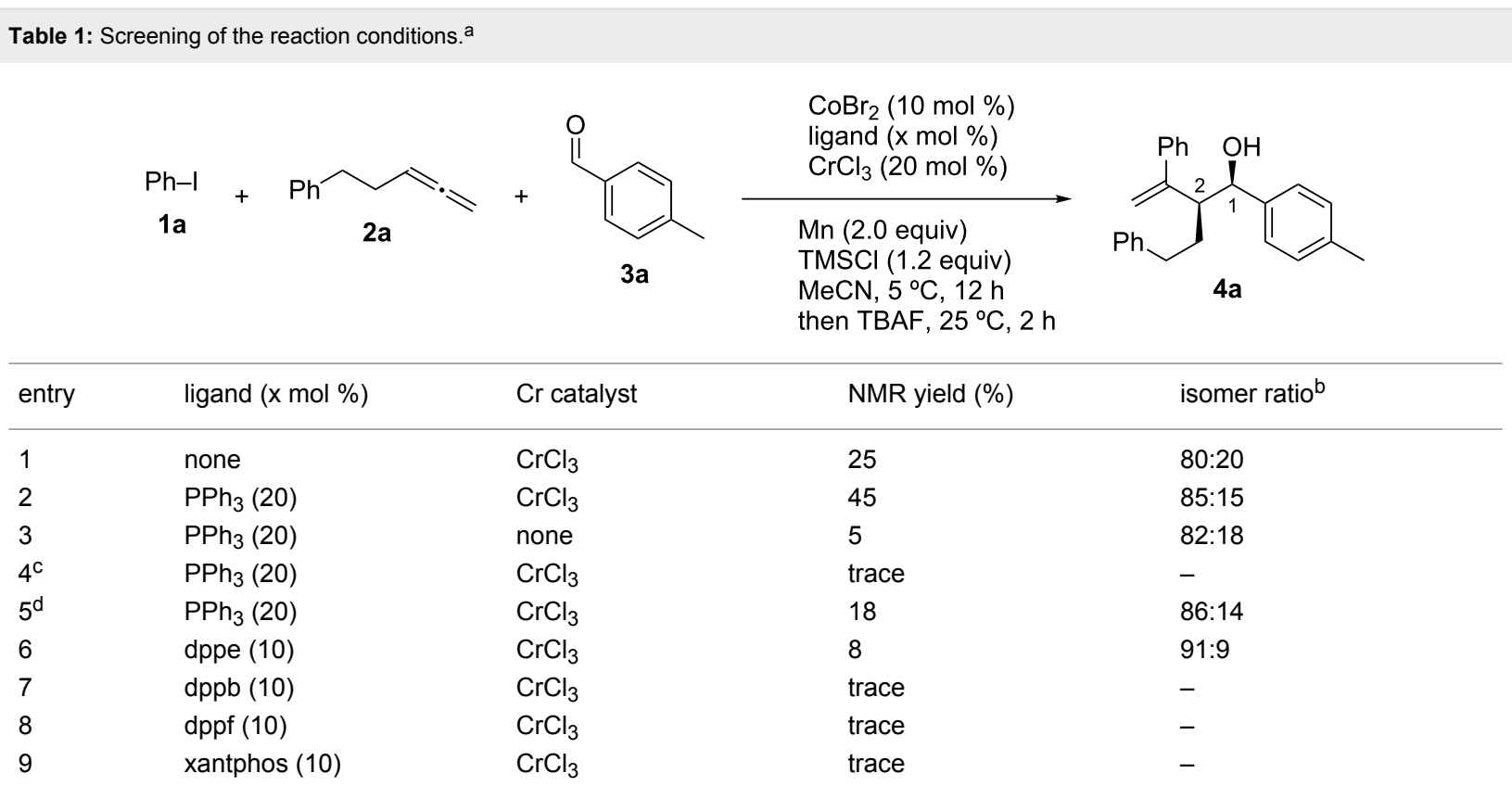




\begin{tabular}{|c|c|c|c|c|}
\hline 10 & 2,2'-bpy (10) & $\mathrm{CrCl}_{3}$ & 45 & $92: 8$ \\
\hline 11 & L1 (10) & $\mathrm{CrCl}_{3}$ & 52 & $93: 7$ \\
\hline 12 & L2 (10) & $\mathrm{CrCl}_{3}$ & 64 & 91:9 \\
\hline 13 & L3 (10) & $\mathrm{CrCl}_{3}$ & 69 & 92:8 \\
\hline $14^{\mathrm{e}}$ & - & $\mathrm{CrCl}_{3}$ & 65 & 91:9 \\
\hline 15 & L3 (10) & $\mathrm{CrCl}_{3}(\mathrm{bpy})$ & 48 & $94: 6$ \\
\hline 16 & L3 (10) & $\mathrm{CrCl}_{3}(\mathrm{~L} 3)$ & 24 & $92: 8$ \\
\hline 17 & L3 (10) & $\mathrm{Cr}$ (salen)Cl & 21 & $91: 9$ \\
\hline
\end{tabular}

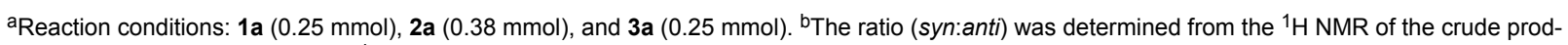
uct. ${ }^{C} \mathrm{Zn}$ was used instead of $\mathrm{Mn}$. ${ }^{\mathrm{d}}$ Without the presence of $\mathrm{TMSCl}^{\mathrm{e}} \mathrm{CoBr}_{2}$ (L3) was used instead of $\mathrm{CoBr}_{2}$.
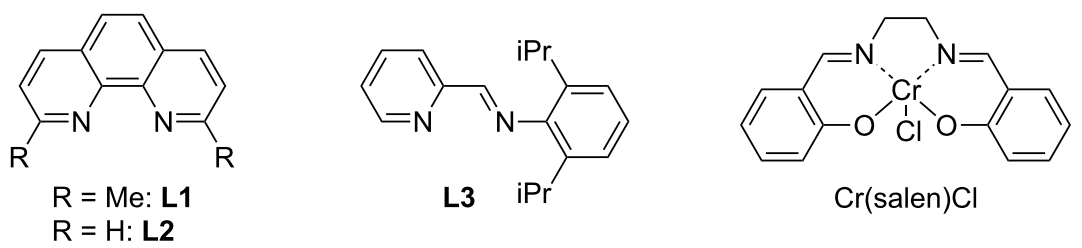

highly dependent on the solvent used; for example, dimethylformamide (DMF), tetrahydrofuran (THF), 1,4-dioxane, and toluene did not result in any formation of $\mathbf{4 a}$.

With the optimized conditions in hand, the use of aldehydes in the $\mathrm{Co} / \mathrm{Cr}$-catalyzed three-component coupling reaction was explored, as shown in Scheme 6. Electron-rich and electrondeficient aryl aldehydes, as well as 2-furylaldehyde, were well tolerated in the reaction, leading to the formation of the corre- sponding homoallylic alcohols with similar diastereomer ratios (4a-f). Additionally, alkyl aldehydes were also successfully used in the coupling reaction, albeit resulting in slightly lower yields (4g, 4g', 4g" and $\mathbf{4 h}$ ). Next, the generality of the reaction was investigated using aryl iodides (Scheme 7) and allenes (Scheme 8). Although aryl bromides and chlorides did not participate in the coupling, a diverse set of functional groups such as methoxy $(\mathbf{4 j} \mathbf{j})$, halogens (4k and $\mathbf{4 l})$, trifluoromethyl (4m), cyano (4n), and ester (4o) substituents at the para-posi-

\footnotetext{
Scheme 6: Screening of aldehydes in the $\mathrm{Co/Cr-catalyzed} \mathrm{three-component} \mathrm{coupling} \mathrm{reaction.} \mathrm{All} \mathrm{yields} \mathrm{are} \mathrm{determined} \mathrm{after} \mathrm{isolation.} \mathrm{The} \mathrm{values} \mathrm{in}$
} 


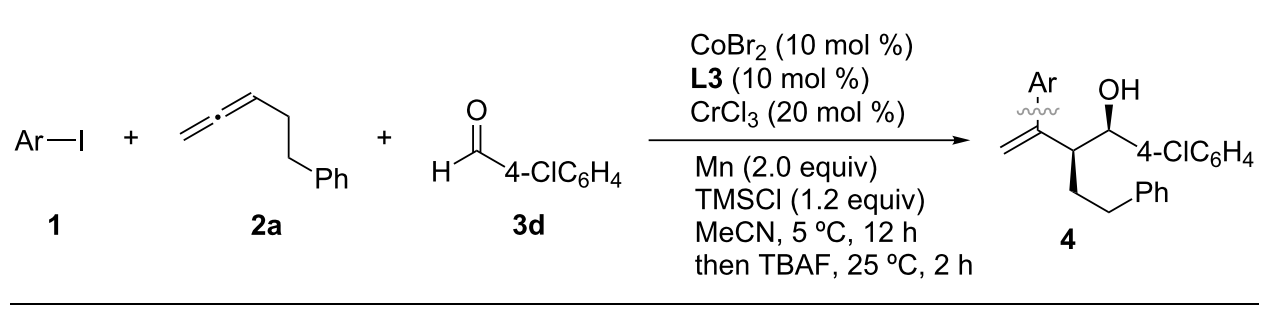<smiles>C=C(c1ccccc1)C(CCc1ccccc1)C(O)C(C)(C)CC</smiles>

4i, $70 \%$ [92:8]<smiles>FC(F)(F)c1ccc(C(F)(F)F)cc1</smiles>

$4 m, 65 \%[85: 15]$<smiles>Cc1cccc(C#N)c1</smiles>

4q, $53 \%[85: 15]$<smiles>COc1ccc(C(C)(C)C)cc1</smiles>

4j, 51\% [81:29]<smiles>CC(C)(C)c1ccc(C#N)cc1</smiles>

4n, $65 \%$ [85:15]<smiles>CC(F)(Cl)c1cccc(F)c1</smiles>

$4 r, 78 \%$ [91:9]<smiles>CC(C)(C)c1ccc(Cl)cc1</smiles>

4k, 76\% [90:10]<smiles>CC(=O)c1ccc(C(C)(F)F)cc1</smiles>

4o, $47 \%[88: 12]$<smiles>FC(F)(F)c1cccc(C(F)(F)F)c1</smiles>

4s, $58 \%[84: 16]$<smiles>CC(C)(C)c1ccc(F)cc1</smiles>

4I, $79 \%[87: 13]$<smiles>Cc1cccc(C(C)(C)C)c1</smiles>

$4 p, 58 \%[88: 12]$<smiles>Cc1ccccc1C(C)(C)C</smiles>

4t, $60 \%$ [99:1]

Scheme 7: Screening of aryl iodides in the Co/Cr-catalyzed three-component coupling reaction. All yields are determined after isolation. The values in brackets indicate the diastereomer ratio of the syn and anti products, determined from ${ }^{1} \mathrm{H}$ NMR spectra.

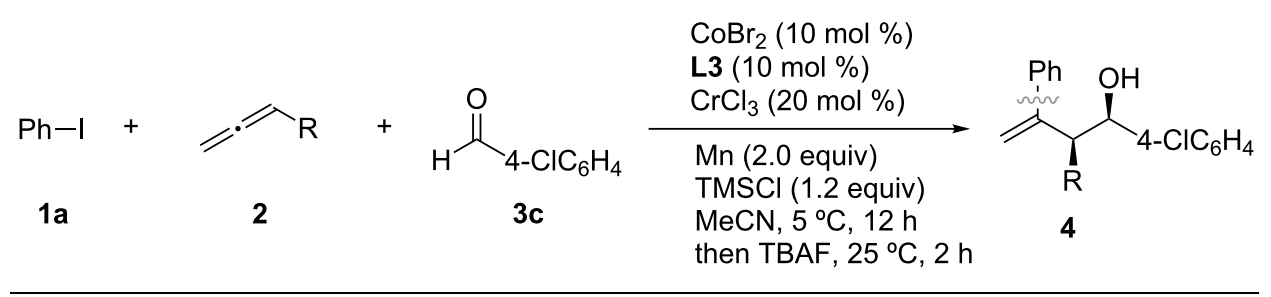

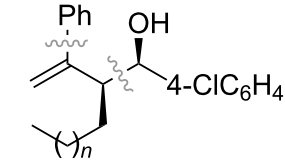

4u $(n=6), 70 \%$ [98:2]

4u' $(n=11), 60 \%$ [98:2]<smiles>C=C(C)C(CCOS(=O)(=O)F)C(C)C</smiles>

$4 v, 56 \%$ [92:8]<smiles>C=C(C)C(CNP)C(C)I</smiles>

$4 w, 45 \%$ [85:15]

Scheme 8: Screening of allenes in the Co/Cr-catalyzed three-component coupling reaction. All yields are determined after isolation. The values in brackets indicate the diastereomer ratio of the syn and anti products, determined from ${ }^{1} \mathrm{H}$ NMR.

tion of the phenyl ring were successfully used in the reaction, giving rise to the desired coupling products in good yields (47-79\%). The homoallylic alcohols $\mathbf{4 p - t}$ were formed with a high degree of syn-selectivity because of meta- and orthosubstituted aryl iodides also being well tolerated in the reaction. The protocol was not only limited to the coupling of simple allenes; it was also used with heteroatom-containing functionalized allenes to afford the $s y n$-homoallylic alcohols $\mathbf{4 u}, \mathbf{4} \mathbf{u}$ ' and $\mathbf{4 w}$ in reasonably good yields (Scheme 8).

During the investigation of allenes, it was observed that, when oxygen substituents were present at the allenyl position, cou- 
pling products with reversed diastereoselectivity were obtained (Scheme 9). Thus, treatment of 4-benzyloxybuta-1,2-diene (5) with 1 and 3a under identical reaction conditions mainly afforded the anti-configured homoallylic alcohols 7-10 in $46-65 \%$ yield. A similar reversed diastereoselectivity was observed in the coupling reaction of silyloxy allene $\mathbf{6}$, leading to 11 in $46 \%$ yield (anti/syn $=73: 27)$.

A stoichiometric reaction using phenylchromium(II or III) reagents, generated from the reaction of $\mathrm{CrCl}_{2}$ or $\mathrm{CrCl}_{3}(\text { thf })_{2}$ with phenyllithium $[19,20]$, in the presence of allene $\mathbf{2 a}$ and aldehyde $3 \mathbf{c}$ provided diarylmethanes in $78-85 \%$ yields without the visible consumption of allene $\mathbf{2 a}$ (Scheme 10, reaction 1). Furthermore, in the absence of the $\mathrm{CrCl}_{3}$ catalyst, allene $\mathbf{2 a}$ was utterly consumed, whereas most of iodide 1a and aldehyde 3d were recovered unreacted (Scheme 10, reaction 2). These results indicate that the arylcobalt, rather than the arylchromium intermediate, promoted the allene carbometalation. Additionally, it is thought that the vinylcobalt generated was converted to vinylchromium, which would be inactive in the oligomeriza- tion, but is a highly nucleophilic species. According to these findings, the reversed diastereoselectivity in Scheme 9 might be due to stereoelectronic effects $[21,22]$. Thus, the $\sigma^{*}(\mathrm{C}-\mathrm{O})$ bond stabilizes the forming $\sigma(\mathrm{Co}-\mathrm{C})$ bond in the transition state $\mathbf{C}$ of the carbocobaltation step (Scheme 11), facilitating the further selective formation of the branched allylcobalt species $\mathbf{D}$ which could be converted into the thermodynamically more stable $(E)$ allylcobalt species $\mathbf{E}$ because of the flexible C(vinyl)-C(allyl) single bond. The generated compound $\mathbf{E}$ then undergoes transmetalation with the chromium salt to give the $(E)$-allylchromium species $\mathbf{F}$. In contrast, the carbometalation of a simple allene produces $(Z)$-allylcobalt species $\mathbf{E}^{\prime}$ and the corresponding ( $Z$ )-allylchromium product $\mathbf{F}^{\prime}$ would be provided through a transition state such as $\mathbf{C}^{\prime}$, in which the cobalt center is connected to a less sterically hindered terminal allene carbon [23].

On the basis of these results, a plausible catalytic cycle for the cobalt/chromium-catalyzed three-component coupling reaction is shown in Scheme 12. The three-component coupling starts

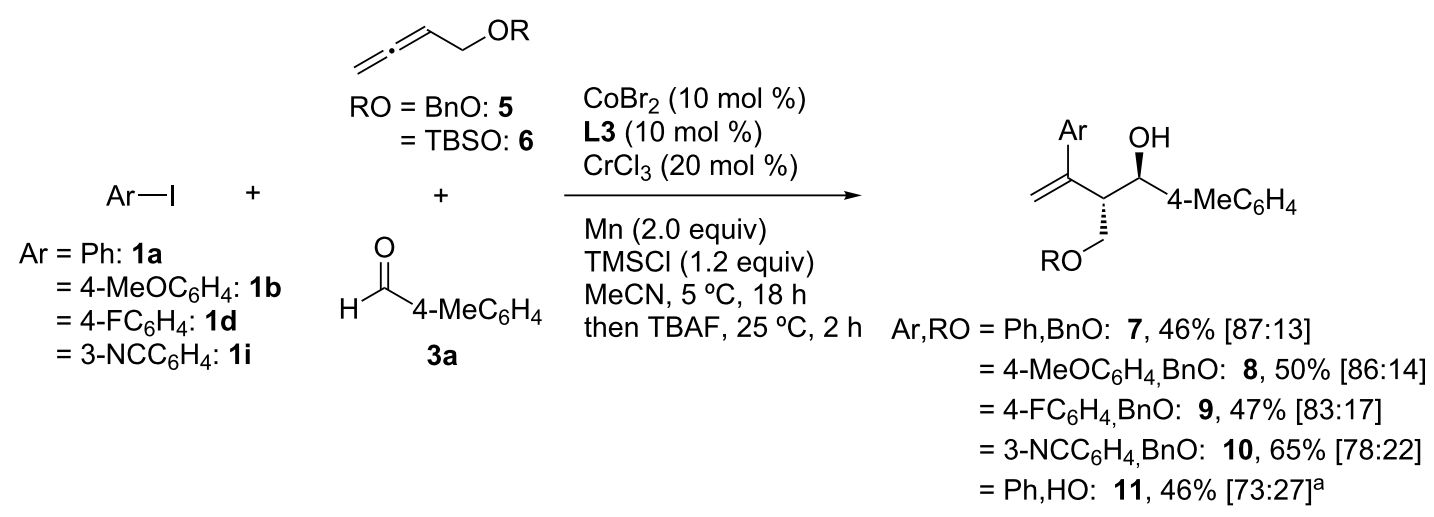

Scheme 9: Reversed diastereoselectivity using allenyl ethers 5 and $\mathbf{6}$. ${ }^{4} 4$-chlorobenzaldehyde was used instead of $3 \mathbf{a}$.

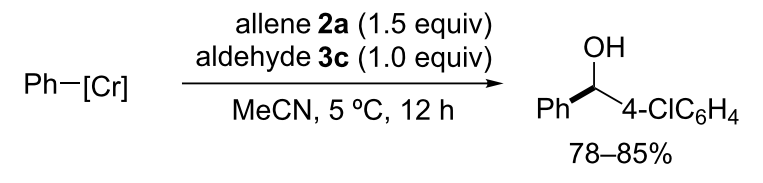

(1)

$78-85 \%$

\begin{tabular}{|c|c|c|}
\hline $\begin{array}{l}1 \mathrm{a} \\
+\end{array}$ & $\begin{array}{l}\mathrm{CoBr}_{2}(10 \mathrm{~mol} \%) \\
\text { L3 }(10 \mathrm{~mol} \%)\end{array}$ & \\
\hline $\begin{array}{l}\mathbf{2 a}(1.5 \text { equiv }) \\
+ \\
3 \mathbf{d}\end{array}$ & $\begin{array}{l}\text { Mn (2.0 equiv) } \\
\text { TMSCI (1.2 equiv) } \\
\text { MeCN, } 5^{\circ} \mathrm{C}, 18 \mathrm{~h}\end{array}$ & no product \\
\hline
\end{tabular}

(2)

Scheme 10: Stoichiometric reaction of phenylchromium(II or III) reagents (reaction 1) and the three-component coupling without $\mathrm{CrCl}_{3}$ catalyst (reaction 2). 


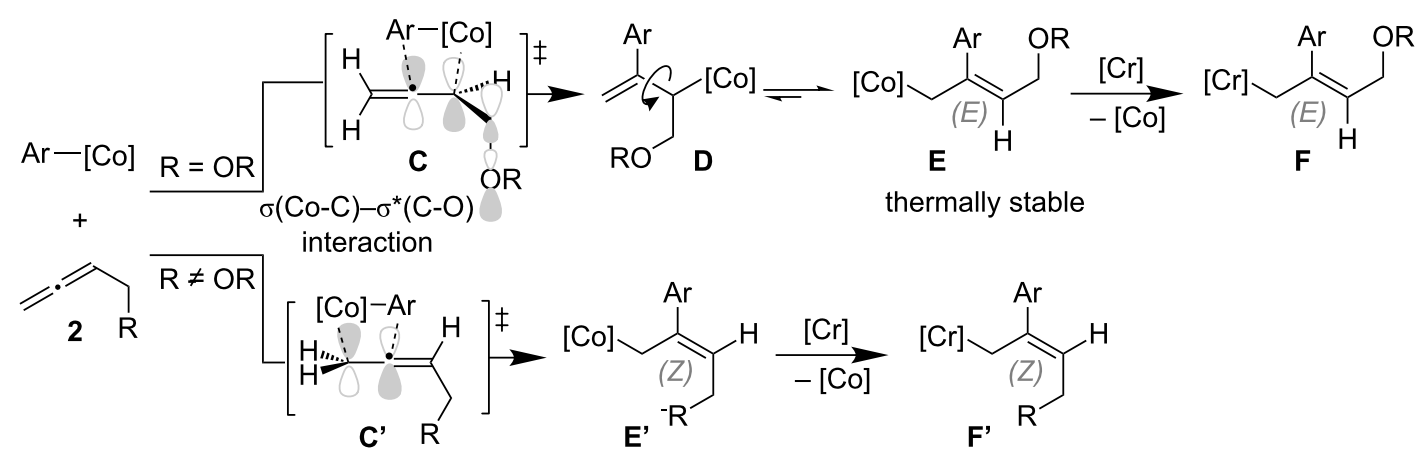

Scheme 11: The origin of the diastereoselectivity in the present three-component coupling.

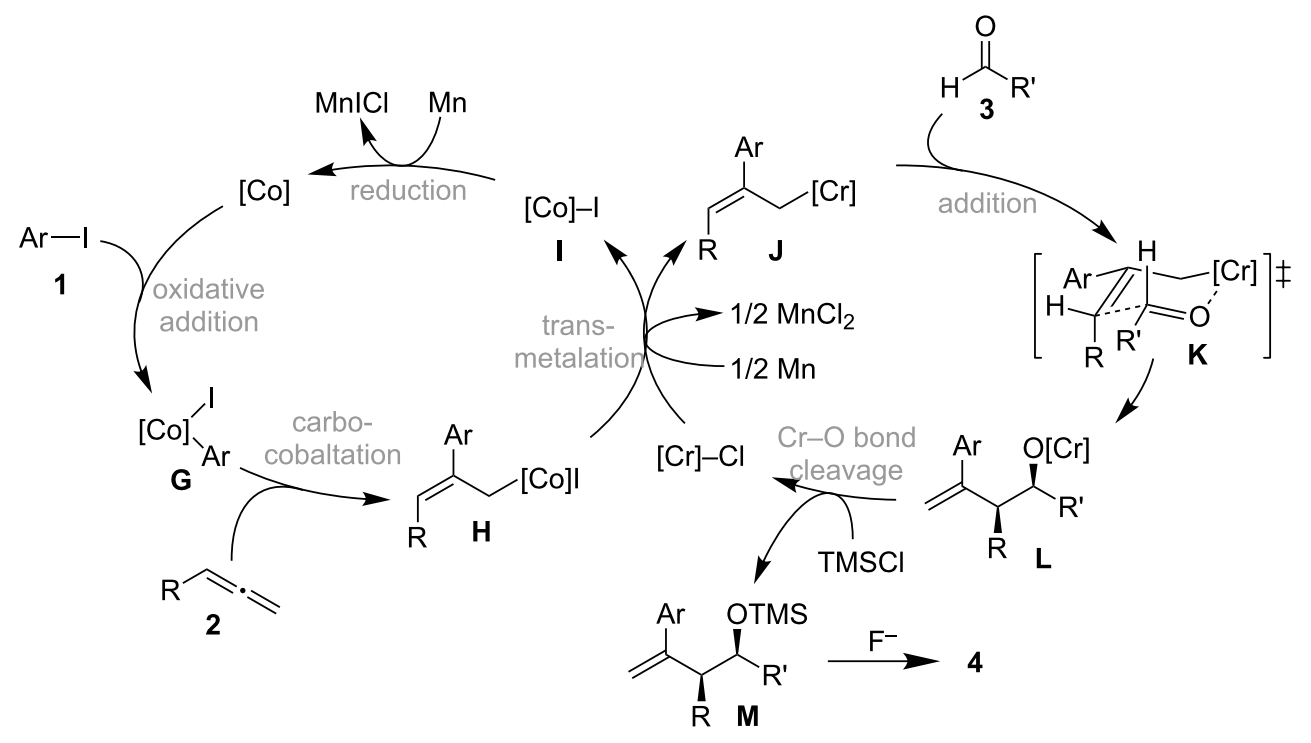

Scheme 12: Plausible reaction mechanism of the three-component coupling.

with the oxidative addition of an aryl iodide $\mathbf{1}$ to a low-valent cobalt species to form an arylcobalt species $\mathbf{G}$ that reacts with an allene $\mathbf{2}$ to stereoselectively generate an allylcobalt $\mathbf{H}$ via carbocobaltation. Rapid transmetalation between $\mathbf{H}$ and the chromium salt $[8,9]$ triggers the transfer of the cobalt allyl group to the chromium to afford $\mathbf{I}$ and the highly nucleophilic allylchromium species $\mathbf{J}$, which retains the same stereochemical information on the olefinic moiety as that of $\mathbf{H}$. The allylchromium species $\mathbf{J}$ reacts with the aldehyde $\mathbf{3}$ at the $\gamma$-position of the allyl metal unit via a cyclic six-membered transition state $\mathbf{K}$ to give the chromium alkoxide $\mathbf{L}$ [24]. Finally, the $\mathrm{Cr}-\mathrm{O}$ bond is cleaved by TMSCl, generating the active chromium salt for the transmetalation and the silyl ether $\mathbf{M}$, the desilylation of which with a fluoride anion results in the formation of a homoallylic alcohol 4.

\section{Conclusion}

The cobalt/chromium-catalyzed three-component coupling reaction of aryl iodides, allenes, and aldehydes to produce highly substituted homoallylic alcohols in a diastereoselective manner has been demonstrated. In the coupling reaction, two catalysts played individual roles; the cobalt catalyst activated aryl iodides to form arylcobalt species, which then performed allene carbocobaltation to form stereo-defined substituted ( $Z$ )-allylcobalt intermediates. The chromium catalyst transformed the generated allylcobalt intermediates into highly nucleophilic allylchromium species, without the isomerization of the olefinic moiety, via transmetalation between the generated allylcobalt intermediate and the chromium salt. Moreover, it was found that an oxygen atom present at the allenyl position resulted in a reversed diastereoselectivity of the homoallylic alcohol prod- 
ucts; thus, the allene carbocobaltation regioselectivity could be controlled by the stereoelectronic interaction between the forming $\sigma(\mathrm{C}-\mathrm{Co})$ bond and a neighboring $\sigma^{*}(\mathrm{C}-\mathrm{O})$ bond. Further mechanistic studies and expansion of the substrate scope, including synthetic applications of this three-component coupling, are currently in progress.

\section{Supporting Information}

\section{Supporting Information File 1}

Experimental part.

[https://www.beilstein-journals.org/bjoc/content/

supplementary/1860-5397-14-118-S1.pdf]

\section{ORCID ${ }^{\circledR}$ iDs}

Kimihiro Komeyama - https://orcid.org/0000-0001-7111-2112

Itaru Osaka - https://orcid.org/0000-0002-9879-2098

\section{References}

1. Takai, K. Bull. Chem. Soc. Jpn. 2015, 88, 1511. doi:10.1246/bcsj.20150170

2. Flynn, A. B.; Ogilvie, W. W. Chem. Rev. 2007, 107, 4698. doi:10.1021/cr050051k

3. Tamaru, Y. Modern Organonickel Chemistry; Wiley-VCH: Weinheim, Germany, 2005.

4. Okude, Y.; Hirano, S.; Hiyama, T.; Nozaki, H. J. Am. Chem. Soc. 1977, 99, 3179. doi:10.1021/ja00451a061

5. Jin, H.; Uenishi, J.; Christ, W. J.; Kishi, Y. J. Am. Chem. Soc. 1986, 108, 5644. doi:10.1021/ja00278a057

6. Takai, K.; Tagashira, M.; Kuroda, T.; Oshima, K.; Utimoto, K.; Nozaki, H. J. Am. Chem. Soc. 1986, 108, 6048. doi:10.1021/ja00279a068

7. Fürstner, A.; Shi, N. J. Am. Chem. Soc. 1996, 118, 12349. doi:10.1021/ja9625236

8. Takai, K.; Nitta, K.; Fujimura, O.; Utimoto, K. J. Org. Chem. 1989, 54, 4732. doi:10.1021/jo00281a004

9. Usanov, D. L.; Yamamoto, H. Angew. Chem., Int. Ed. 2010, 49, 8169. doi:10.1002/anie.201002751

10. Takai, K.; Matsukawa, N.; Takahashi, A.; Fujii, T. Angew. Chem., Int. Ed. 1998, 37, 152. doi:10.1002/(SICI)1521-3773(19980202)37:1/2<152::AID-ANIE152>3.0 .CO;2-8

11. Takai, K.; Toratsu, C. J. Org. Chem. 1998, 63, 6450. doi:10.1021/jo9814086

12. Xiong, Y.; Zhang, G. J. Am. Chem. Soc. 2018, 140, 2735. doi:10.1021/jacs.7b12760

13. Komeyama, K.; Kashihara, T.; Takaki, K. Tetrahedron Lett. 2013, 54, 5659. doi:10.1016/j.tetlet.2013.07.133

14. Komeyama, K.; Okamoto, Y.; Takaki, K. Angew. Chem., Int. Ed. 2014, 53, 11325. doi:10.1002/anie.201406807

15. Komeyama, K.; Asakura, R.; Fukuoka, H.; Takaki, K. Tetrahedron Lett. 2015, 56, 1735. doi:10.1016/j.tetlet.2015.02.101

16. Komeyama, K.; Kiguchi, S.; Takaki, K. Chem. Commun. 2016, 52, 7009. doi:10.1039/c6cc03086f
17. Hopkins, C. D.; Malinakova, H. C. Org. Lett. 2004, 6, 2221. doi:10.1021/ol0492795

18. Fillon, H.; Gosmini, C.; Périchon, J. J. Am. Chem. Soc. 2003, 125, 3867. doi:10.1021/ja0289494

19. Daly, J. J.; Sneeden, R. P. A.; Zeiss, H. H. J. Am. Chem. Soc. 1966, 88, 4287. doi:10.1021/ja00970a049

20. Kanno, K.-i.; Liu, Y.; lesato, A.; Nakajima, K.; Takahashi, T. Org. Lett. 2005, 7, 5453. doi:10.1021/ol052214x

21. Ito, H.; Ito, S.; Sasaki, Y.; Matsuura, K.; Sawamura, M. J. Am. Chem. Soc. 2007, 129, 14856. doi:10.1021/ja076634o

22. Ohmiya, H.; Makida, Y.; Li, D.; Tanabe, M.; Sawamura, M. J. Am. Chem. Soc. 2010, 132, 879. doi:10.1021/ja9092264

23. Yoshida, Y.; Murakami, K.; Yorimitsu, H.; Oshima, K. J. Am. Chem. Soc. 2010, 132, 8878. doi:10.1021/ja102303s

24. Hiyama, T.; Kimura, K.; Nozaki, H. Tetrahedron Lett. 1981, 22, 1037. doi:10.1016/S0040-4039(01)82859-8

\section{License and Terms}

This is an Open Access article under the terms of the Creative Commons Attribution License

(http://creativecommons.org/licenses/by/4.0), which permits unrestricted use, distribution, and reproduction in any medium, provided the original work is properly cited.

The license is subject to the Beilstein Journal of Organic Chemistry terms and conditions:

(https://www.beilstein-journals.org/bjoc)

The definitive version of this article is the electronic one which can be found at: doi: $10.3762 /$ bjoc. 14.118 